\title{
Importance of routes of exposure in the development of immune response to peanut
}

\author{
Nivedita Khanna ${ }^{1,2^{*}}$, Jeremy A Scott ${ }^{1,2,3}$ \\ From AllerGen NCE Inc.'s Fifth Annual Research Conference: Innovation from Cell to Society \\ Québec City, QC, Canada. 7-9 February 2010
}

\begin{abstract}
Background
Immediate hypersensitivity reactions to food are a major health concern for Canadians due to severity of reactions they elicit and their increasing prevalence. Currently $6 \%$ of children develop food allergy. Peanut (PN) hypersensitivity is one of the major causes of foodrelated anaphylaxis. We tested the hypothesis that the route of initial exposure to food antigen dictates the nature of the immune response and hence the development of an allergic response/anaphylaxis $v s$. tolerance upon subsequent or secondary exposure. The aim of this study was to: 1) establish three independent animal models of peanut exposure via the oral, dermal and inhalational routes that will allow us to 2) investigate whether sensitization or tolerance develops following gastrointestinal, dermal or inhalational exposures, following initial exposures via the alternate route.
\end{abstract}

\section{Methods}

Female Balb/c mice (8-weeks old) were sensitized to 1 $\mathrm{mg}$ of PN protein in combination with $5 \mu \mathrm{g}$ cholera toxin as an adjuvant or PBS on days 0 and 14 via the oral, dermal or intranasal routes; and challenged with crude peanut extract (CPE) by oral gavage $(2 \mathrm{mg})$, dermally $(10 \mu \mathrm{g})$ or intranasally $(500 \mu \mathrm{g})$ on days $28,30,32$, 35, 37 and 39. Mice were assessed for allergy/anaphylaxis (i.e., rectal temperature at 10 minute intervals, scoring for clinical symptoms of anaphylaxis) for 40 minutes after the last allergen challenge and then euthanized for: 1) general (e.g., measurement of PN-specific immunoglobulins, plasma histamine and inflammatory cell infiltration into the target organ), and 2) route-specific end-points (i.e., measurement of wheal diameter and pulmonary function testing using the flexiVent after

'Divisions of Occupational and Respiratory Medicine, Department of Medicine, University of Toronto, Canada

Full list of author information is available at the end of the article dermal and nasal challenge, respectively). A previously established murine model of peanut anaphylaxis was used as the positive control [1]. Data are expressed as the mean \pm SEM ( $n=12-16 /$ group $)$.

\section{Results}

Oral sensitization followed by oral challenge evoked the most clinically potent allergic reaction, as compared with dermal or nasal challenge (mean clinical scores of $1.7 \pm 0.1,1.0 \pm 0.3$ and $0.06 \pm 0.04$, respectively). To investigate peanut-specific humoral immune response we measured serum IgE and IgG subclass levels. Intragastric sensitization with peanut extract induced a significant IgE response $(125.9 \pm 21.7 \mathrm{ng} / \mathrm{mL})$, whereas nasal or cutaneous priming favored elevated levels of the IgG subclasses. Higher IgG1/G2a ratios (10-25 folds within the cross sensitization/challenge groups) indicated Th2 polarization of the immune response. PN sensitization and challenge by all three routes resulted in similar increases of plasma histamine upon secondary challenge. Oral or nasal priming triggered greater inflammatory cell infiltration in the peritoneal cavity upon oral challenge. Dermal and nasal priming preferentially resulted in more severe skin inflammation as assessed by wheal diameter, compared with orally-sensitized animals. Upon inhalational challenge, orally-sensitized mice exhibited greater cellular infiltration into the airways with predominantly neutrophilic influx, whereas nasal sensitization favored mild eosinophilia in the BAL. However, PN priming via these routes and subsequent challenge did not affect methacholine responsiveness of the airways.

\section{Conclusions}

Our observations indicate that 1) oral sensitization is the most likely to elicit a significant allergic response to peanut upon secondary challenge, dermal sensitization is 
less likely; nasal sensitization results in an intermediate likelihood. 2) Oral sensitization resulted in higher production of allergen-specific IgE antibodies, whereas nasal or cutaneous sensitization induced greater IgG responses; higher IgG1/G2a ratios point to Th2 biased response. 3) Initial exposure via the oral route triggered neutrophilia, while inhalational priming elicited an eosinophilic influx into the target organs. Comparison of the immune and cellular mediators of tolerance and anaphylaxis via the different routes may help to identify the causative mediator/cell population that could lead to novel therapeutic targets for intervention.

\section{Acknowledgements}

AllerGen NCE, Canadian Group on Food and Allergy Research (CanGoFAR) and the Keenan Research Centre in the Li Ka Shing Knowledge Institute at St. Michael's Hospital.

\section{Author details}

${ }^{1}$ Divisions of Occupational and Respiratory Medicine, Department of Medicine, University of Toronto, Canada. ${ }^{2}$ Keenan Research Centre in the Li Ka Shing Knowledge Institute and the Gage Occupational and Environmental Health Unit, St. Michael's Hospital Research Centre, Canada. ${ }^{3}$ Occupational and Environmental Health Program, Dalla Lana School of

Public Health, University of Toronto, Canada.

Published: 26 November 2010

\section{Reference}

1. Sun J, et al: J Immunol 2007, 179:6696-703.

doi:10.1186/1710-1492-6-S3-P19

Cite this article as: Khanna and Scott: Importance of routes of exposure in the development of immune response to peanut. Allergy, Asthma \& Clinical Immunology 2010 6(Suppl 3):P19.

\section{Submit your next manuscript to BioMed Central} and take full advantage of:

- Convenient online submission

- Thorough peer review

- No space constraints or color figure charges

- Immediate publication on acceptance

- Inclusion in PubMed, CAS, Scopus and Google Scholar

- Research which is freely available for redistribution

Submit your manuscript at www.biomedcentral.com/submit 